\title{
Training primary care nurses to conduct alcohol screening and brief interventions in South Africa
}

\author{
K Peltzer \\ Human Sciences Research Council \& University Limpopo
}

\author{
P Seoka \\ University of Limpopo
}

T Babor

University of Connecticut

\section{Obot \\ World Health Organisation}

\section{Keywords:}

Alcohol, screening, brief intervention, atrisk drinking, problem drinking, training, nurses, South Africa

\section{Correspondence address:}

Prof Karl Peltzer

Chief Research Specialist

Social Aspects of HIV/AIDS and Health

Human Sciences Research Council

Private Bag X9182

Cape Town 8000

South Africa

Tel: (021) 467-4420

Fax: (021) 467-4424

E-mail: KPeltzer@hsrc.ac.za

\section{Abstract: Curationis 29(2): 16-21}

Although progress has been made in developing a scientific basis for alcohol screening and brief intervention (SBI), training packages are necessary for its widespread dissemination in primary care settings in developing societies. Using a training package developed by the World Health Organisation 121 nurses from one rural site (29 clinics in Vhembe District) and one urban site (3 clinics and 6 mobile clinics in Polokwane/ Seshego) in South Africa were compared before and after SBI training regarding knowledge and attitudes, and the subsequent practice of SBI in routine clinical practice. Although the training effects were at times moderate, all changes were in a direction more conducive to implementing SBI. Health care providers significantly increased in knowledge, confidence in SBI and higher self-efficacy in implementing SBI at followup after 9 months after receiving the training. When delivered in the context of a comprehensive SBI implementation programme, this training is effective in changing providers' knowledge, attitudes, and practice of SBI for at-risk drinking.

\section{Acknowledgements}

The authors wish to thank the World Health Organisation and the University of Limpopo Research Administration for their support of the project upon which this article is based. Joyce Tlakula is thanked for her support from the Limpopo Provincial Department of Health and Welfare.

\section{Introduction}

Adult per capita consumption of absolute alcohol in South Africa is between 9 and 10 litres per year, which places the country among the higher alcohol consuming nations. Since 1993 the level of per capita adult absolute alcohol consumption appears to be rising, after a decrease in 1990 and 1991 (Myers \& Parry 2002: 3). Based on the findings of the Department of Health's South African Demographic and Health Survey (SADHS) conducted in 1998 by the
Medical Research Council (1998: 15), just under half of men $(45 \%)$ and one-fifth of women (17\%) 15 years and older report that they currently consume alcohol. Peltzer (1999: 98) found that in primary care rural clinics in the Limpopo Province that past 6 months alcohol use among men was $72.5 \%$ and among women $9 \%$, and of those $31 \%$ of the men and $9 \%$ of the women engaged in hazardous drinking. Hazardous drinking is a pattern of alcohol consumption that increases the risk of harmful consequences for the user or others (Babor, Campbell, Room \& 
Saunders 1994: 22). From this primary care sample of current substance users $61 \%$ of the men indicated that their drinking or drug use had caused a family problem, $58 \%$ needed to drink or use drugs more and more for effect, $33 \%$ of men and $7 \%$ of women felt they had a drinking or drug problem now and $15 \%$ had a family member with a drinking or drug problem. Only a few had sought help for their substance abuse problem (men: 10\%; women: $2 \%$ ) from the following sources: friend, pastor, relative, traditional/faith healer, and nurse. None had ever undergone treatment for their substance abuse problem.

The White Paper for Transformation of the Health System in South Africa (Department of Health 1997: 25) and the National Drug Master Plan (Department of Welfare 1999: 3) in South Africa have prioritised prevention and management of alcohol abuse and the integration of substance abuse management in primary health care. The Department of Health (2001: 34) has included in the service description of clinics the prevention and management of substance abuse. Standards for primary health care include health-learning materials on alcohol in local languages and competence of health staff in identifying alcohol abuse and provide basic counselling for behaviour changes and referral to nongovernmental organisations specializing in substance abuse.

Alcohol consumption in amounts that significantly increase the chances of health problems (i.e., at-risk drinking) is common among patients presenting to primary care, and imposes a significant economic burden on the health care system (Fleming, Mundt, French, BaierManwell, Stauffacher \& Lawton-Barry 2000: 7). Primary health care is the first point of contact of individuals, families and communities in most countries' health systems (Kaner, Wutzke, Saunders, Powell, Morawski \& Bouix 2001: 621). Primary care is therefore a particularly valuable point of delivery for community-based interventions for excessive alcohol consumption due both to its universality and also to the large proportion of the population who access it each year (Department of Health 2001: 35). Moreover, problem drinkers present to primary health care twice as often as other patients and constitute approximately $20 \%$ of patients on practice lists (Anderson 1993: 263).

Screening procedures (asking patients routinely, e.g. about the amount and frequency of alcohol use) have been developed to identify at-risk drinkers (e.g., Babor, Higgins-Biddle, Saunders, \& Monteiro 2001: 2ff.), and significant reductions in drinking and related risks can be achieved by brief interventions (e.g., Moyer, Finney, Swearingen, \& Vergun 2001: 279). Screening for alcohol consumption among patients in primary care carries many potential benefits. It provides an opportunity to educate patients about low-risk consumption levels and the risks of excessive alcohol use. Information about the amount and frequency of alcohol consumptions may inform the diagnosis of the patient's presenting condition, and it may alert clinicians to the need to advise patients whose alcohol consumption might adversely affect their use of medications and other aspects of their treatment. Screening can also identify persons likely to be alcohol dependent, and referral for diagnostic evaluation may encourage patients to seek treatments that have been shown to be effective (Babor, Higgins-Biddle, Saunders \& Monteiro 2001: 6). Brief interventions are characterized by their low intensity and short duration. They typically consist of one to three sessions of counselling and education. They are intended to provide early intervention, before or soon after the onset of alcohol-related problems. Most programmes are designed to motivate high-risk drinkers to moderate their alcohol consumption, rather than to promote total abstinence with specialized treatment techniques. Brief interventions also provide a valuable framework to facilitate referral of severe cases of alcohol dependence to specialized treatment (Babor et al. 2003: 212).

Introducing new screening and prevention activities into primary care practices presents significant logistical, attitudinal, and behavioural challenges. Many nurses feel inadequately trained when faced with patients who have alcohol-related problems (Church \& Babor 1995: 278; Rendall-Mkosi, Siegfried, \& Allen, 2003: 31). Barriers to adequate coverage of alcohol-related problems in both nursing schools and continuing professional education include traditional attitudes about the moral culpability of chronic alcoholics, confusion as to whether problem drinking is a medical or psychiatric concern, lack of faculty role models, lack of training materials, and role ambiguity regarding who is responsible for screening and intervention (Bendtsen \& Akerlind 1999: 795). Another factor could be the relative lack of awareness that Screening and Brief Intervention (SBI) leads to significant reductions in drinking and risk.

Research on medical education has shown that training can be effective in improving health providers' knowledge and skills in addressing alcohol issues (Ockene, Wheeler, Adams, Hurley, \& Hebert 1997: 2334) but changes in knowledge may be easier to produce than changes in attitudes and behaviour (El-Geubaly, Toews, Lockyer, Armstrong, \& Hodgins 2000: 949). Kaner et al. (2001: 621) found that greater exposure to alcohol-related continuing medical education appears to have resulted in better diagnosis and more appropriate management of alcohol-related problems by general practitioners (GPs). A recent review of the components and outcomes of medical education in substance-related disorders concluded that the selection of a combined didactic and interactive educational strategy may be the most cost-effective learning strategy, but there is little empirical evidence to support this approach (El-Geubaly et al. 2000: 949).

Although some progress has been made in the development and dissemination of SBI in industrial countries (Babor \& Higgins-Biddle 2000: 677, Kaner et al. 2001: 621), this study evaluates the dissemination of the development of successful training packages that include programme implementation procedures in a developing country. The WHO SBI programme was developed to train medical providers to implement SBI in primary care settings. In this article we evaluate the effects of this programme on nurses in South Africa, as part of a World Health Organization Collaborative Study on Brief Interventions for Hazardous and Harmful Alcohol Use in developing countries (Monteiro \& Gomel 1998: 5). It describes the effects of the programme on trainees' knowledge and attitudes, and the subsequent practice of SBI in routine clinical practice.

\section{Methods}

\section{Research setting}

The study, conducted between 2003 and 2004 , involved the implementation and evaluation of the WHO Screening and Brief Intervention (SBI) programme in one rural and one urban site in the Limpopo 
Province, South Africa. The sites were chosen purposefully representing one rural and one urban health service area. The rural site was in one of four municipalities of Vhembe district (which has a population of 1097621 ), the Makhado local municipality with a population of 497077 . A section of the Makhado local municipality was chosen, the Elim area with one hospital and 29 primary health care centres that is 2 health centres and 27 clinics. It is predominantly occupied by African speaking Tsivenda and Xitsonga, as well as few Afrikaans speaking white farmers living farming units within the area. The urban site is in one of five municipalities (Polokwane) in the Capricorn district. The latest census reported a population of 832474 for the District. One portion of the Polokwane municipality with a population figure of 424976 has been selected to pilot the SBI project, Focusing mainly on two major urban areas, that is Polokwane city and Seshego Township with the two public hospitals, one health center, 3 clinics and 6 mobile clinics. The area comprise of Northern Sotho speaking Africans who are in the majority, followed by Afrikaans and English speaking Whites, Coloureds and Indians. The staff in the health centres and clinics consisted of professional and assistant nurses, not doctors. In a representative community survey in the project area, Peltzer, Seoka and Mashego (2004: 705) found using a cut-off score of 8 for the Alcohol Use Disorders Identification Test (AUDIT) that $27 \%$ of all men and $6.4 \%$ of all women were found to be problem drinkers.

\section{Sample and procedure}

The training participants consisted of 121 nurses, 86 professional nurses (chief, senior and professional nurses) and 19 enrolled nurses and 10 assistant nurses. Eighty-two nurses were trained from 29 clinics in Vhembe District and 45 from 3 clinics and 6 mobile clinics in Polokwane/ Seshego. This was $38.7 \%$ of all the nurses $(n=314)$ of the 35 clinics. First all managers of all the clinics were trained, and thereafter, additional nurses (at least two) per clinic were trained. Clinic managers selected their staff (one at a time) to attend additional trainings in a central venue. Most trainee nurses were women $(90.9 \%)$ and $8.3 \%$ were men. Their mean age was 39.8 years $(\mathrm{SD}=8.6)$, with an age range of 23 to 62 years, and their mean years of professional practice was 14.3 years $(\mathrm{SD}=9.3)$.

The evaluation of the effects of training and programme implementation were measured prior and by the same health care providers 9 months after the training, with a self-administered questionnaire. One of the researchers (PS) administered the questionnaire to the nurses prior to the trainings in a central venue and at follow-up in the clinics. All nurses were contacted at follow-up twice. The response rate was $67 \%$ ). Informed consent was taken from participants. Nurses were given a consent form to sign after reading the purpose of the study. Ethics approval was obtained from the University of Limpopo Ethics Committee and the Provincial Department of Health and Welfare.

\section{Training curriculum and trainers}

It takes a practical, systems approach, aiming to facilitate the implementation of SBI in clinic operations rather than merely educating staff. The training curriculum contains modules addressing practical issues deemed essential to implementing the programme.

For early identification of alcohol problems in primary care the Alcohol Use Disorders Identification Test (AUDIT) (Babor et al. 2001: 2ff.) and for the brief intervention the WHO brief intervention package for hazardous and harmful drinking (Babor \& Higgins-Biddle 2001: $2 \mathrm{ff}$.) were used. Both were adapted to the South African context, e.g. in terms of standard unit of alcoholic drink and drinking limits. The AUDIT was translated and back translated according to scientific standard procedures (Brislin 1980: 392) into four of the major languages (Tsonga, Northern Sotho, Venda, and Afrikaans) in the project area. The self-help booklet for patients and a handout on "cutting back" showing the drinking limits and health effects of risky alcohol consumption were also made available in the target languages.

The AUDIT manual explains the purpose of screening for alcohol problems in primary care, the context of alcohol screening, the development and validation of the AUDIT, administration guidelines, scoring and interpretation.

The Brief Intervention manual defines concepts and terms, roles and responsibilities of Primary Health Care, SBI: a risk management and case finding approach, alcohol education for low-risk drinkers, abstainers and others, simple advice for risk zone II drinkers (AUDIT scores between 8 and 15 are most appropriate for simple advice focused on the reduction of hazardous drinking), brief counselling for risk zone III drinkers (AUDIT scores between 16 and 19 suggest brief counselling and continued monitoring), referral for risk zone IV drinkers (AUDIT scores of 20 or above clearly warrant further diagnostic evaluation for alcohol dependence), patient education, self-help booklet and training sources.

Critical administrative activities included administration and scoring of the screening instruments, assuring availability of patient brochures, sequencing of interventions with treatment of presenting health problems, the essential elements of an intervention, and the management of SBI records.

A nurse and a psychologist trainer (PS) delivered all the 14 trainings, with a duration of six hours each. A project site consultant (KP) ensured by periodic supervison of the trainings that the trainers followed the standardised training curriculum. Follow-up supervisory and support visits were also provided by one of the trainers (PS).

Quality assurance of training was conducted by analysing transcribed tape-recordings of 40 nurses-patient SBI interactions. By comparing the implementation efficacy of SBI with the training curriculum the researchers assessed the quality of the training.

\section{Measures}

The self-administered questionnaire used consisted of the following components:

Knowledge on alcohol use and problems ( 8 items). For example, trainees were asked to define moderate drinking in terms of the South African upper limit of number of drinks per day for men. Preand post-training knowledge items were scored according to the number of correct responses.

Further, a 54-item questionnaire informed by the alcohol health services literature including Project NEADA (Church \& Babor 1995: 280) and the World Health Organization Study of General Practitioners (Monteiro \& Gomel 1998: 8) measured a variety of other factors that might affect a clinician's ability to provide SBI to patients, as follows:

\section{Confidence in screening of alcohol use} (5 items), for example: "Asking questions to collect information about a patient's risk for alcohol related problems." (response options from $1=$ no confidence to $4=$ quite a lot of confidence), 
Table 1. Means (standard deviation) of pre- and post training scale scores for knowledge, confidence, perceived obstacles, self-efficacy and expectations/benefits

\begin{tabular}{|l|l|l|l|}
\hline Scale & Pre-training (N=121) & Post-training (N=81) & T \\
\hline Objective knowledge (range0=8) & $3.9(1.5)$ & $4.8(1.9)$ & $3.22^{* *}$ \\
\hline Confidence in screening (range 1-4) & $2.0(0.4)$ & $2.9(0.8)$ & $3.14^{* *}$ \\
\hline Confidence in brief intervention (range 1-4) & $2.7(1.2)$ & $3.2(0.5)$ & $2.61^{*}$ \\
\hline Perceived obstacles to screening (range 1-5) & $3.4(0.6)$ & $3.2(0.5)$ & -1.63 \\
\hline Perceived obstacles to brief intervention (range 1-5) & $3.3(0.5)$ & $3.1(0.4)$ & -1.88 \\
\hline Self-efficacy in SBI (range 1-5) & $3.0(0.5)$ & $3.5(0.5)$ & $2.88^{* *}$ \\
\hline Expectations of SBI benefit (range 1-5) & $4.1(0.9)$ & $4.3(0.7)$ & 1.54 \\
\hline
\end{tabular}

$* * \mathrm{p}<.01,{ }^{*} \mathrm{p}<.05$

Confidence in Brief intervention with alcohol problems (5 items), for example: "Stating medical concerns about a patient's drinking pattern and related health risks."

(response options from $1=$ no confidence to $4=$ quite a lot of confidence),

Perceived obstacles to screening alcohol use (15 items), for example: "I feel it is an invasion of privacy to ask patients questions about their alcohol consumption."

(response options from $1=$ strongly agree to $5=$ strongly disagree),

Perceived obstacles to brief intervention with alcohol problems (19 items), for example: "In general, health care providers cannot do much to get patients to reduce their drinking." (response options from $1=$ strongly agree to $5=$ strongly disagree);

Self-efficacy in SBI (5 items), for example: "I feel I can appropriately advise patients about drinking and its effects." (response options from $1=$ strongly agree to $5=$ strongly disagree, reverse scored)

Expectations of SBI benefit (5 items), for example: "Stating my medical concerns about a patient's drinking habits and related health risks will result in their cutting back on their drinking." (response options from $1=$ strongly agree to $5=$ strongly disagree, reverse scored).

Internal consistency of all scales used here were above .70 prior to and at nine months after the training in this sample. Finally, the self-administered questionnaire included questions about socio-demographic and professional background, screening and brief intervention practices (e.g. the uptake of SBI and the number of cases managed with SBI) as well as open-ended questions on perceived barriers and support in implementing SBI.

\section{Data analysis}

Group means of the knowledge, confidence, perceived obstacles, selfefficacy and benefits scales were compared across time (before and nine months after training) using a Paired Samples T-Test.

\section{Results}

Table 1 shows the average scores for the measures of knowledge, confidence, perceived obstacles, self-efficacy and expectations before and after nine months of the training exercise. Health care providers significantly increased in knowledge, confidence in screening and brief intervention and higher self-efficacy in implementing SBI at follow-up after 9 months after receiving the training. Participants also decreased levels of perceived obstacles for implementing $\mathrm{SBI}$, and raised their level of expectations relative to their respective baseline scores, though not at significant levels.

\section{Uptake of SBI}

At follow-up 81 nurses were surveyed regarding the implementation of SBI in their clinics. All indicated to have takenup SBI. Most $(82 \%)$ had referred a patient with probable alcohol dependence to a hospital, though 18 percent indicated that they did not know where to refer.

Nurses were asked at baseline and followup how many patients they had managed for alcohol problems in the past nine months. At follow-up significantly more cases had been managed as compared to prior to the training (see Table 2).

\section{Implementation barriers and support}

At follow-up nurses reported as main barriers to screening and brief intervention: patient-caused (55\%) (disinterested/refused) and shortage of staff/work overload (35\%), and some (10\%) mentioned that patients at risk do not come to the clinic.

Regarding barriers to referral $63 \%$ of the nurses noted that they "don't use them/ like them (being referred)" and lack of adequate services for the treatment of alcoholic patients $(24 \%)$. Most $(74 \%)$ nurses screen patients during consultation, whenever they have time $(21 \%)$ and after consultation (5\%). Most $(71 \%)$ record the screening results on provided log sheets, $14 \%$ in the record book, and $5 \%$ on the AUDIT sheet.

The most supporting elements for helping the programme succeed were cooperation from colleagues $(31 \%)$, support from facilitators and supervisors (29\%), and training (19\%). The most hindering elements for the programme's success were rated as patient-caused (withhold/give wrong information/ refuse) $(54 \%)$ and work overload $(46 \%)$. One-third indicated that the programme works okay, one-third that either only specific staff or all staff should be trained and one-third that it should be widely advertised in the community.

\section{Discussion}

The results of this study demonstrate that even relatively short training of health care providers in screening and brief intervention techniques can result in gains in provider knowledge, selfefficacy, and expectations about the value of $\mathrm{SBI}$. 
There was also a decrease, though not significantly, in perceived obstacles to performing brief interventions with patients. More importantly, these shortterm changes in attitudes and confidence were associated with an increase in provider behaviour of increased implementation of SBI. Perhaps booster training sessions and more supervisory support visits could have strengthened the SBI programme that could also have addressed the expressed barriers in the implementation of SBI by the nurses. A number of clinics are terribly short staffed so that time is limited for SBI. Andersen, Kaner, Wutzke, Wensing, Grol, Heather and Saunders (2003: 597) found among GPs that those who received more education on alcohol, who perceived their working environment as supportive, who expressed higher role security in working with alcohol problems and who reported greater therapeutic commitment to working with alcohol problems were more likely to manage patients with alcohol-related harm.

For practicing health care providers, the various belief changes for the nurses could be attributed in part to the opportunities to implement SBI in their clinical practices after the training. To the extent that training increases knowledge of effective practices, enhances confidence in performing them, and decreases perceived obstacles to SBI, the training program should produce positive changes in practice behaviour. The results are consistent with other studies of provider behaviour which show that health care providers trained in a brief, provider-delivered alcohol intervention will counsel their at-risk patients when cued to do so and when supported by a primary care office system. Our results also replicate previous findings that changes in provider behaviour are associated with parallel changes in providers' attitudes, knowledge and counselling skills following a group training programme (Aalto, Pekuri \& Seppä 2001 305, Babor, Higgins-Biddle, Higgins, Gassman \& Gould 2004: 20).

Although the results suggest that training in alcohol SBI results in positive changes in attitudes, knowledge, selfefficacy and clinical behaviour, the findings are subject to the limitations of a pre-post research design that relies primarily on self-report information providers. There was some attrition between the training and follow-up questionnaires, which may have resulted in a biased selection of nurses who were more responsive to the training.

Studies have shown the efficacy and cost effectiveness of SBI in primary care, but little progress has been made in disseminating and implementing this clinical preventive Table 2: In the past nine months adult patients managed specifically for heavy drinking or alcoholrelated problems

\begin{tabular}{|l|l|l|}
\hline No of patients & Pre-training (\%) & Follow-up (\%) \\
\hline None & 55.0 & 29.3 \\
\hline $1-5$ & 26.2 & 39.8 \\
\hline $6-11$ & 6.7 & 18.0 \\
\hline $12-24$ & 4.5 & 4.3 \\
\hline $25-49$ & 4.3 & 4.3 \\
\hline 50 or more & 3.2 & 4.1 \\
\hline
\end{tabular}
service (Babor et al. 2004: 24). The results of this study indicate that the training of nurses is feasible, and it is effective in preparing health care providers to implement an SBI programme in South Africa. There are, however, other pre-requisites that must be met before SBI will find widespread application in primary care practice. Standards of practice by national accrediting and professional organizations are needed. Purchasers and payers must encourage this preventative health service and provide financial incentives to providers. Linkages to community-based organizations and hospitals must be developed to support referral for treatment in an integrated service delivery system. Communications and social marketing must enlist patients in the search for better preventative health services. And finally, research will be required to develop more efficient ways to train present and future nurses in the implementation of SBI in ways that assure improved performance in practice in South Africa.

\section{References}

AALTO, M; PEKURI, P \& SEPPÄ, K 2001: Primary health care nurses' and physicians' attitudes, knowledge and beliefs regarding brief intervention for heavy drinkers. Addiction, 96: 305-311.

ANDERSON, P 1993: Management of alcohol problems: the role of the general practitioner. Alcohol and Alcoholism. 28: 263-272.

ANDERSON,P; KANER,E; WUTZKE, S; WENSING,M; GROL, R; HEATHER, N \& SAUNDERS, J 2003: Attitudes and management of alcohol problems in general practice: descriptive analysis on findings of a World Health Organization international collaborative survey.
Alcohol \& Alcoholism. 38: 597-601.

BABOR, TF \& HIGGINS-BIDDLE, JC 2000: Alcohol screening and brief intervention: dissemination strategies for medical practice and public health. Addiction. 95(5): 677-686.

BABOR, TF \& HIGGINS-BIDDLE, JC 2001: Brief intervention for hazardous and harmful drinking. A manual for use in primary care settings. World Health Organization, Geneva, Department of Mental Health and Substance Dependence. WHO/MSD/MSB/01.6b.

BABOR, TF; CAMPBELL, R; ROOM, R \& SAUNDERS, J (Eds.) 1994: Lexicon of alcohol and drug terms. Geneva: World Health Organisation.

BABOR, TF; HIGGINS-BIDLE, JC; SAUNDERS, JB \& MONTEIRO, MG 2001: AUDIT: The Alcohol Use Disorders Identification Test. Guidelines for use in primary care. World Health Organization, Geneva, Department of Mental Health and Substance Dependence. WHO/MSD/MSB/01.6a.

BABOR, TF; HIGGINS-BIDDLE, JC; HIGGINS, PS; GASSMAN, RA \& GOULD, BE 2004: Training medical providers to conduct alcohol screening and brief interventions. Substance Abuse, 25(1): 17-26.

BABOR, T; CAETANO, R; CASSWELL, S; EDWARDS, G; GGIESBRECHT, N; GRAHAM, K; GRUBE, J; GRUENEWALD, P; HILL, I; HOLDER, H; HOMEI, R; ÕSTERBERG,E; REHM, J; ROOM, R \& ROSSOW, I 2003: Alcohol: no ordinary commodityresearch and public policy. Oxford: Oxford University Press. 
BENDTSEN, P \& AKERLIND, I 1999: Changes in attitudes and practices in primary health care with regard to early intervention for problem drinkers. Alcohol \& Alcoholism. 34(5): 795-800.

BRISLIN, RW 1980: Translation and content analysis of oral and written material. In: TRIANDIS, H.C. \& BERRY, J.W. (Eds.) Handbook of cross-cultural psychology, Vol. 1(Pp 389-444). Boston: Allyn and Bacon.

CHURCH, O \& BABOR, T 1995: Barriers and breakthroughs: Substance abuse curricula in nursing education. Journal of Nursing Education. 34: 27881.

DEPARTMENT OF HEALTH 1997: The White Paper for transformation of the health system in South Africa. Pretoria: Department of Health.

DEPARTMENT OF HEALTH 2001: The Primary Health Care package for South Africa- a set of norms and standards. Pretoria: Department of Health.

DEPARTMENT OF WELFARE 1999: National Drug Master Plan. Pretoria: Department of Welfare.

EL-GEUBALY, B; TOEWS, J; LOCKYER, J; ARMSTRONG, S \& HODGINS, D 2000: Medical education in substance-related disorders: components and outcome. Addiction. 95(6): 949-57.

\section{FLEMING,M;MUNDT,M;FRENCH,M; BAIER-MANWEI I I STAUFFACHER, E \& LAWTON-BARRY, K 2000: Benefit-cost analysis of brief physician advice with problem drinkers in primary care settings. Medical Care. 38(1): 7-18.}

KANER, EFS; WUTZKE, S; SAUNDERS, JB; POWELL, A; MORAWSKI, J \& BOUIX, JC 2001: Impact of alcohol education and training on general practitioners' diagnostic and management skills: findings from a World Health Organization Collaborative Study. Journal of Studies on Alcohol. 62: 621627.

MEDICAL RESEARCH COUNCIL 1998: South Africa demographic and health survey. Pretoria: Dept of Health.

World Health Organization project on brief interventions for alcohol-related problems in primary health care settings. Journal of Substance Abuse. 3: 5-9.

MOYER,A; FINNEY,J;SWEARINGEN, C \& VERGUN P. 2001: Brief interventions for alcohol problems: A meta-analytic review of controlled investigations in treatment-seeking and non-treatment-seeking populations. Addiction. 97: 279-292.

MYERS, B \& PARRY, C 2002: Fact sheet: alcohol use in South Africa. Accessed from www.healthnet.org.za, 3 October 2003.

OCKENE,J; WHEELER,E; ADAMS,A; HURLEY, T \& HEBERT, J 1997: Provider training for patient centered alcohol counseling in a primary care setting. Archives of Internal Medicine. 157: 2334-41.

PELTZER, K. 1999: Substance use in rural primary health care patients in the Northern Province. In: C.D.H. PARRY, A. BHANA, J. BALLEY, H. POTGIETER \& M. LOWRIE (Eds.) South African Community Epidemiology Network on Drug Use (SACENDU) Monitoring alcohol and drug abuse trends. Proceedings of Report Back Meeting, March (Phase 5)(pp. 94-102). Tygerberg: Medical Research Council.

PELTZER, K; SEOKA,P \& MASHEGO, T-AB 2004: Prevalence of alcohol use in a rural South African community. Psychological Reports, 95: 705-706.

RENDALL-MKOSI, KM \& SIEGFRIED, N \& ALLEN, S 2003: Sensible drinking project: evaluation of health workers training. African Journal of Drug \& Alcohol Studies. 2: 31-45. 